\title{
HIV testing rates among pregnant women in Managua, Nicaragua, 2010-2011
}

\author{
Jonathan Colasanti, ${ }^{1}$ Marco Lorio Rugama, ${ }^{2}$ Karina Lifschitz, ${ }^{3}$ \\ Manuel Largaespada, ${ }^{4}$ Benito Flores-Lopéz, ${ }^{5}$ Christopher Dodd, ${ }^{6}$ \\ Daniel J. Feaster, ${ }^{7}$ Margaret Pereyra, ${ }^{8}$ and Lisa R. Metsch ${ }^{8}$
}

Suggested citation Colasanti J, Lorio Rugama M, Lifschitz K, Largaespada M, Flores-Lopéz B, Dodd C, et al. HIV testing rates among pregnant women in Managua, Nicaragua, 2010-2011. Rev Panam Salud Publica. 2013;33(1):15-21.

ABSTRACT Objective. To determine and report the rate and pattern of HIV testing among pregnant women receiving ambulatory prenatal care, and the total number of positive cases in pregnant women in Managua, Nicaragua.

Methods. A retrospective epidemiological review was conducted to assess HIV testing rates among pregnant women in Managua attending district-level health centers in 2010 and 2011, with a focus on a single district (District 6.1).

Results. A total of $39.4 \%$ of pregnant women receiving prenatal care at Managua health centers in 2010 received an HIV test, and this number increased to $49.8 \%$ in 2011 ( $\mathrm{P}<0.001$; phi statistic, 0.10). In 2010, 27 pregnant women in Managua were found to be HIV positive, corresponding to $0.17 \%$ of those who were tested. In 2011, 31 tested positive $(0.12 \%$ of those who were tested). Comparisons between 2010 and 2011 at the District 6.1 level reflect an increase in women who received HIV tests from 24.2\% in 2010 to $49.3 \%$ in 2011 ( $\mathrm{P}<0.001$; phi statistic, 0.26). In District 6.1, two pregnant women were identified as HIV positive in 2010 and three in 2011, corresponding to $0.32 \%$ and $0.13 \%$ of pregnant women tested, respectively.

Conclusions. Despite significant improvements in HIV testing rates from 2010 to 2011, the numbers tested remain below the goal recommended by the Pan American Health Organization (PAHO) in order to achieve virtual elimination of mother-to-child transmission by 2015 (> 95\%). Patterns of testing demonstrated increased rates coinciding with a health fair in District 6.1, but effects were short-lived. Therefore, new approaches are necessary to bolster prenatal HIV screening efforts within Managua and District 6.1 in Nicaragua.

\section{Key words}

HIV seroprevalence; pregnant women; AIDS serodiagnosis; Nicaragua.

\footnotetext{
${ }^{1}$ Department of Medicine, University of Miami, Florida, United States of America. Send correspondence to: Jonathan Colasanti, jacolasanti@med.miami.edu

2 Hospital Dr. Roberto Calderón Gutiérrez, Managua, Nicaragua.

${ }^{3}$ Division of Neonatology, Department of Pediatrics, University of Miami, Miami, Florida, United States of America.

${ }^{4}$ Departamento de VIH y ITS, Sistema Local de Atención Integral en Salud (SILAIS), Managua, Nicaragua.

5 Centro de Salud "Silvia Ferrufino," Managua, Nicaragua.

${ }^{6}$ Division of General Internal Medicine, Department of Medicine, University of Washington, Seattle, Washington, United States of America.
}

Worldwide, there are 33.4 million HIV-positive people, of which approximately 52\% are women (1). Although transmission from mother to child is largely preventable, with an achievable

\footnotetext{
7 Division of Biostatistics, Department of Epidemiology and Public Health, Miller School of Medicine, University of Miami, Miami, Florida, United States of America.

${ }^{8}$ Department of Epidemiology and Public Health, University of Miami, Miami, Florida, United States of America.
}

rate of less than $2 \%$ if appropriate services are in place (2), in 2009 an estimated 370000 children were newly infected (1). The Pan American Health Organization (PAHO) goal of eliminating mother-to-child transmission of HIV by 2015 calls for increasing HIV testing rates among pregnant women to greater than 95\%, among other strategies (3). In Nicaragua, a lower-middle income country, early detection of HIV-positive 
pregnant women falls short of this goal $(4,5)$, with only $35.0 \%$ and $50.8 \%$ of pregnant women across the country in 2008 and 2009 respectively receiving an HIV test (6).

As the second-poorest country in the western hemisphere, Nicaragua has a concentrated HIV epidemic, with a prevalence of $0.2 \%$ (5, 7-9). According to the U.S. Agency for International Development (USAID), the estimated number of HIV cases increased from 3700 in 2001 to 7700 in June 2010 (8). The Nicaraguan Ministry of Health (Ministerio de Salud, MINSA) reported 6406 detected cases as of 1 December 2011 (10). The first case of HIV in Nicaragua was reported in 1987, later than other Central American countries (e.g., Costa Rica, 1983; El Salvador, 1984; Guatemala, 1984; Honduras, 1985; and Belize, 1986) (8, 11-13). Incidence remained low during the first five years of the epidemic but gradually increased in the subsequent five-year period (19931998) (7). During the period from 2000 to 2004, however, average annual incidence skyrocketed to $495 \%$ of the prior four years (9).

The delay in rising incidence of HIV in Nicaragua is best understood within a historical context. A revolution took place countrywide during the latter part of the 1970s, followed by a counterrevolution that accompanied a trade embargo and economic blockade by the United States through the mid-1980s (8). The national isolation brought on by these events, combined with low HIV infection rates in intravenous drug users, a controlled commercial sex trade, and a ban on the sale of blood, likely contributed to the low rate of HIV transmission within Nicaragua during the 1980s (14).

At present, the groups most at risk for HIV in Nicaragua are men who have sex with men (MSM) $(9.3 \%$ prevalence) and commercial sex workers (1.1\%-1.9\% prevalence), similar to the situation found in neighboring countries (8). Despite higher prevalence in certain population subgroups, $74 \%$ of HIV transmission is attributed to unprotected heterosexual intercourse (8). At least $40.0 \%$ of MSM have a female sexual partner, creating a bridge into the female population (8). Initially concentrated in men, Nicaragua's HIV epidemic has become "feminized" over the past few decades, with the ratio of infected men to women falling sharply from $12.5: 1$ in 1987 to the current rate of $1.4: 1(7,10,15)$.
This shift has compelled the Nicaraguan National AIDS program (Plan Estratégico Nacional de ITS-VIH/SIDA, PEN) to include "housewives" as an at-risk group, in addition to the historically higher-risk groups of commercial sex workers and MSM (7). This trend underscores the importance of Nicaragua progressing toward PAHO's guidelines of $>95 \% \mathrm{HIV}$ testing in pregnancy as a crucial component of prevention of mother-to-child transmission (PMTCT) (16).

This study was conducted to determine and report current HIV testing rates among pregnant women receiving ambulatory prenatal care, and total number of positive cases in pregnant women in Managua, Nicaragua. This report focuses on a single health center within one health district (District 6.1), and is based on available data for the years 2010 and 2011. Using data at the district level, the authors also examined the pattern of HIV testing rates over time within District 6.1, where a health fair took place in February 2011.

\section{MATERIALS AND METHODS}

\section{Study population}

Based on the most recent published national census (2005), Nicaragua has a total population of 5.14 million, nearly half of whom live below the poverty line $(5,17)$. Almost one-quarter of the country's population (1 262978 people) lives in the department of Managua (17). More than half $(55 \%)$ of all people living with HIV countrywide live in urban areas, and the department of Managua has the second-highest HIV incidence and prevalence rates in the country (6). The second-largest urban center in Nicaragua-Chinandega-has the highest $\mathrm{HIV}$ incidence and prevalence, but these high percentages occur within a smaller population than that of Managua (6). Therefore, the densely populated urban capital of Managua was chosen for this epidemiological review, with a particular focus on District 6.1, located on the southern border of Lake Nicaragua. District 6.1 has a largely urban poor population of 112036 (18). This district was chosen for study because it has been the focal point of a growing collaboration among the public health system, a local nongovernmental organization (NGO), and researchers from affiliated universities. The study population consists of all pregnant women receiving prenatal care in the public health system within Managua and District 6.1, as captured in the databases utilized for data abstraction.

\section{Study type}

A retrospective epidemiological study was conducted in the department of Managua, with a focus on health district 6.1, from January 2010 through December 2011 .

\section{Database information}

Databases from the local health department in Managua ("SILAIS9 Managua") and the District 6.1 health center in Managua were utilized. SILAIS, which is under the jurisdiction of MINSA and is responsible for the provision and coordination of free health services to Managua's citizens, tracks the number of HIV tests performed on pregnant women, the number of positive tests, and the number of prenatal visits in the public system in Managua, at both the department and municipal level. Prenatal visits are classified as either "initial" visits or "subsequent" visits. The District 6.1 health center in Managua collects the same data for the district level. All data presented here for Managua are department level (i.e., they include the municipality of Managua as well as the surrounding areas comprised by the department of Managua).

\section{Current HIV testing infrastructure}

HIV testing within the country's public system is available at tertiary care hospitals and district health centers, and during MINSA community fairs, but not at the level of community health posts. HIV testing outside the public health system is also available-at private clinics, NGOs, and community-based organizations-but is not reflected in the current data.

\section{Methods}

Department-level epidemiological data (for Managua) were abstracted from the aforementioned SILAIS database, along with district-level data (for District 6.1). The number of 1) initial prenatal visits

\footnotetext{
9 Sistema Local de Atención Integral en Salud (Integrated Local Health Care System). This entity has functions similar to those of county health departments in the United States.
} 
FIGURE 1. Percentage of pregnant women who attended a prenatal visit and received an HIV test, by month, District 6.1 , Managua, Nicaragua, 2010-2011 ${ }^{\mathrm{a}-\mathrm{c}}$

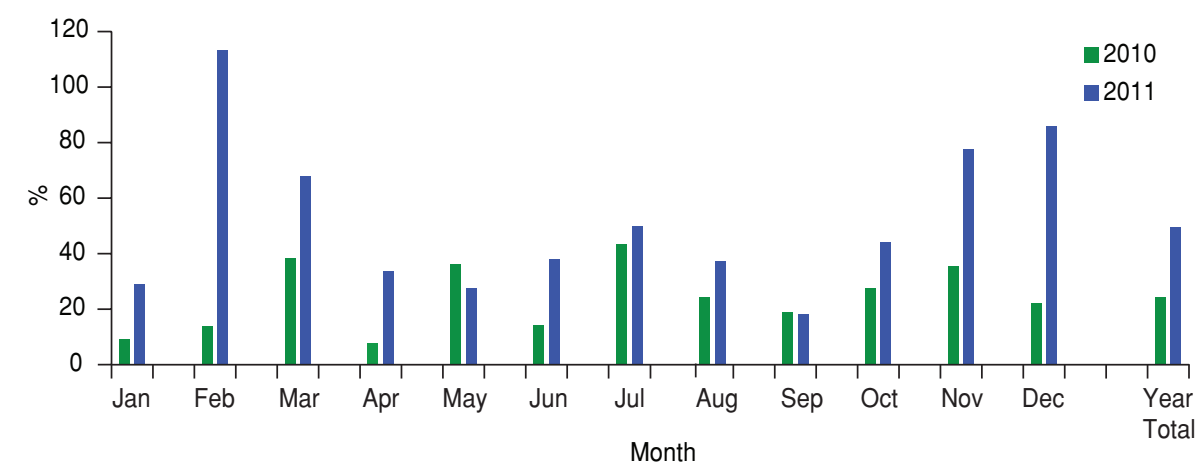

a Last column represents each year in its entirety.

b The increase from 2010 to 2011 was statistically significant $(P<0.001)$.

$c$ The peak in February 2011 corresponds to the staging of district health fairs promoting HIV testing.

FIGURE 2. Percentage of pregnant women who attended a prenatal visit and received an HIV test, by quarter, District 6.1 , Managua, Nicaragua, 2010-2011 a

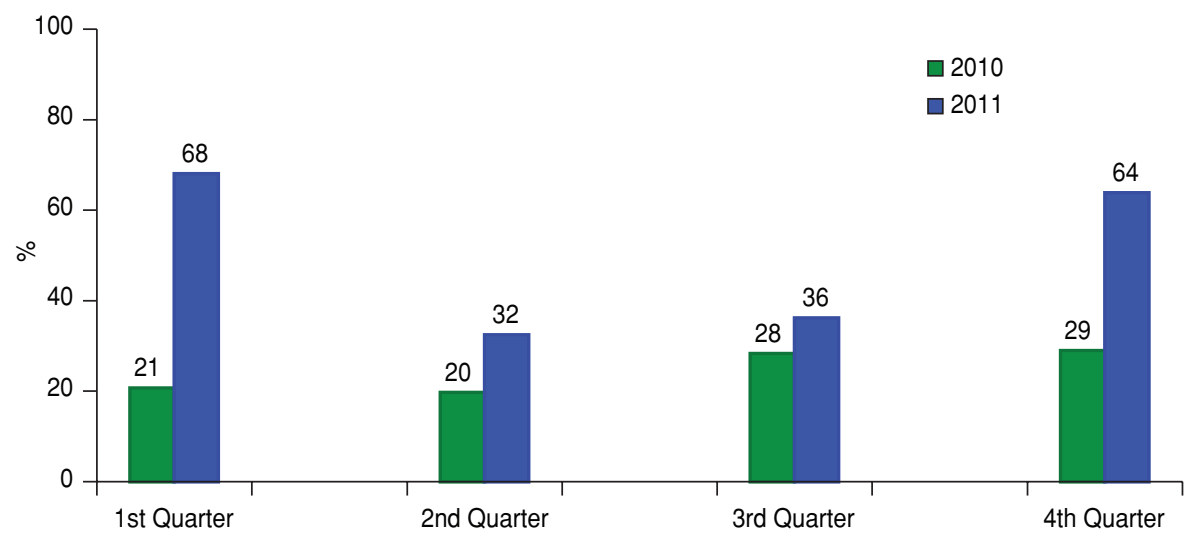

a The increase between each quarter was statistically significant $(P<0.05)$.

and 2) pregnant women receiving an HIV test each month from January 2010 through December 2011 was abstracted from the SILAIS and District 6.1 health center databases. The data abstraction and data entry were verified for accuracy by a second investigator.

To calculate HIV testing rates, the authors used the number of HIV tests conducted with pregnant women, in the ambulatory setting, as the numerator, and the number of initial prenatal visits over the same period as the denominator. Statistical significance for changes in HIV testing rates from 2010 to 2011 was calculated using chi-square analyses, and effect size was measured using the phi test. In additional calculations, the authors included HIV tests completed at hospitals in Managua in the numerator. The total number of confirmed positive HIV tests at the level of both Managua and District 6.1 were abstracted, and the percentage of pregnant women tested with an outcome of a positive test was calculated.

\section{Ethical considerations}

The study was approved by both the University of Miami institutional review board and SILAIS Managua. All data were aggregate and de-identified, so the researchers were unaware of any individual woman's HIV status.

\section{RESULTS}

In Managua, 39.4\% of 27613 pregnant women attending ambulatory prenatal clinic visits at health centers in 2010 received an HIV test. In 2011 there was a statistically significant increase to $49.8 \%$ of 29758 pregnant women $(P<0.001$; phi statistic, 0.10$)$. When tests completed at hospitals in 2010 (5 171) and 2011 (10 690) were included, the percentage of pregnant women tested was $58.1 \%$ in 2010 and $85.7 \%$ in 2011. During 2010, 27 pregnant women in Managua were found to be HIV positive, corresponding to $0.17 \%$ of those who were tested. In 2011,31 or $0.12 \%$ of those who were tested were HIV positive.

Monthly comparisons of the percentage of pregnant women tested in District 6.1 in 2010 and 2011 are shown in Figure 1. Quarterly comparisons (Figure 2) of the percentage of pregnant women tested in the District 6.1 health center for 2010 and 2011 respectively are as follows: first quarter, $20.7 \%$ and $68.1 \%$; second quarter, $19.7 \%$ and $32.5 \%$; third quarter, $28.3 \%$ and $36.2 \%$; and fourth quarter, $29.0 \%$ and $63.8 \%$. All increases from 2010 to 2011 were statistically significant $(P<0.05)$.

Year-to-year comparisons for District 6.1 show an increase in the percentage of women who received an HIV test from 
$24.2 \%$ (of 2555 initial prenatal visits) in 2010 to $49.3 \%$ (of 3038 initial prenatal visits) in 2011 (Figure 1). This increase was statistically significant $(P<0.001)$ and had a moderate effect size (phi statistic, 0.26). Two pregnant women in District 6.1 were identified as HIV positive in 2010 and three were identified in 2011, indicating a seropositive rate of $0.32 \%$ and $0.13 \%$ for all pregnant women tested in 2010 and 2011, respectively.

\section{DISCUSSION}

The increasing incidence of HIV in Nicaragua over the past decade, along with the feminization of the case distribution, has raised concern about the risk for pregnant women and their infants. The increase in testing rates from 2010 to 2011 in Managua and District 6.1 are encouraging and serve as evidence that efforts by MINSA and SILAIS Managua are propelling the district and the department in the right direction. Nonetheless, the percentage of women tested still falls short of the PAHO goal of $>95 \%$.

Figure 1 shows a peak in HIV testing in District 6.1 for February 2011, higher than any other month. This acute peak was not sustained throughout the rest of the year. In February 2011, MINSA sponsored health fairs in District 6 businesses with a focus on HIV testing. Presumably, the drastic difference in testing rates during February can be attributed to these fairs. However, the effect was short-lived, indicating health fairs may not be a long-term, sustainable method of achieving higher rates of HIV testing. Another trend in District 6.1 testing, notable in Figure 2, is that higher percentages of women were tested during the first and fourth quarters of the year versus the two middle quarters. Anecdotal evidence from the leadership of District 6.1 indicates these differences may be attributable to higher motivation to fill quotas at the beginning and end of the year. Both of these trends support the use of HIV testing that can be conducted outside a central laboratory setting, during a prenatal clinic visit, such as provider-initiated testing, accompanied by counseling (19-21).

In Managua, a large increase in the percentage of pregnant women tested is evident when tests conducted at the hospital are included in the analysis. This increase illustrates a potentially interesting phe- nomenon of a large proportion of women being tested in the tertiary care setting rather than the primary care setting. This suggests that many women are not being tested until late in their pregnancy. Decentralized testing has been shown to increase testing uptake in other settings and may have a twofold benefit: 1) identifying HIV-positive pregnant women earlier in their pregnancy and thus decreasing the risk of vertical transmission, and 2) shifting the burden of HIV testing from the tertiary care system to the primary care system $(19,21)$. This finding should be interpreted with caution, however, as it assumes that each HIV test was performed on a woman previously seen at a prenatal visit within one of the health centers in Managua, which may not be the case (e.g., some women tested at the hospital may have traveled from outside Managua). It is also possible that some women were tested twice (once at an ambulatory site and again when presenting to the hospital), which would falsely elevate the percentage tested. This is difficult to ascertain because in accordance with Nicaraguan Law 238, which protects patient confidentiality, MINSA prenatal care forms do not have a space for recording HIV test results (they only collect data on whether or not an HIV test was offered to the patient). As a result, a woman can present to a hospital without knowing her HIV serostatus and would therefore most likely be tested even if she had received a prior test during her pregnancy.

The percentage of pregnant women tested in Managua and District 6.1 that were found to be HIV positive was small. The low rate of positive tests may be false, however, because women at higher risk for infection may not be attending prenatal care visits. Nonetheless, the low percentages suggest the health care system would not be overburdened by HIV-positive pregnant women requiring antiretroviral therapy (ART) if testing rates approached complete coverage. The manageable numbers of HIV-positive cases provide a tremendous opportunity to eliminate mother-to-child transmission, especially in a country that is able to provide antiretrovirals to those in need. ART for pregnant women and children in Nicaragua is guaranteed through an agreement with Brazil (Cooperación Lazos Sur-Sur) (6). Data from 2008-2009 indicate that the national women's hospital in Managua, where all HIV-positive pregnant women are referred, has a very effective PMTCT program, achieving 100\% coverage of ART for the known HIV-positive pregnant population (6).

Trend toward increased HIV testing in pregnant women are a common theme throughout Latin America and the Caribbean. The World Health Organization (WHO) reports an increase in the percentage of estimated pregnant women receiving an HIV test in this region from $29 \%$ in 2005 to $61 \%$ in 2010 (21). The reported rate for Nicaragua during 2010 in that same report is $65 \%$ (21). The discrepancy between the values reported here for Managua and District 6.1 versus the country value reported in the WHO document may indicate that testing uptake in urban settings is not as strong as in other areas of Nicaragua.

To place the numbers reported here for Managua and District 6.1 in perspective, it is also useful to look at other reported percentages within the region. The numbers observed in the current study fall in the mid-range of those from other Central American and Caribbean countries. The percentages of pregnant women tested for HIV across the region are as follows: Cuba 95\%, Panama 85\%, Belize $81 \%$, Costa Rica 78\%, Honduras $62 \%$, El Salvador 56\%, Haiti 51\%, Dominican Republic 41\%, and Guatemala $21 \%$ (21). Considering the fact that some countries have achieved excellent uptake of HIV screening among their pregnant population, it may be prudent for the remaining countries to collaborate and adopt policies that have produced these encouraging results. These percentages also underscore the question of why Nicaragua and, more specifically, Managua and District 6.1, have not been able to achieve testing uptake at the level of other countries in the region.

In many parts of the world, presumed potential barriers to achieving a higher rate of testing uptake are lack of patient knowledge of its importance, and the stigma associated with $\operatorname{HIV}(22,23)$. Yet a national survey conducted in Nicaragua in 2006-2007 suggests woman are educated with regard to HIV, and are willing to be tested. The survey also found that $90.2 \%$ of the women surveyed received care during their pregnancy from a professional (24), 98\% knew about AIDS, and $76 \%$ had heard about HIV testing prior to 
the survey (24). In addition, when a subgroup of the women who had received prenatal care in the previous five years were asked whether the HIV test was offered to them during pregnancy, and whether they had accepted, $32 \%$ said they were offered the test, and $77 \%$ of them had accepted (24). Through their provision of prenatal care, health care providers have a significant window of opportunity to promote HIV testing within the existing public health system. Therefore, provider-initiated HIV testing and counseling among pregnant women may continue to improve testing numbers.

\section{Future directions}

To address the need to improve HIV testing among pregnant women, a pilot project was developed and carried out in District 6.1 to better understand ways to increase testing uptake. The project, known as Una Prueba, Una Mujer-Dos Vidas Salvadas (One Test, One Woman-Two Lives Saved), was developed to evaluate the effects of 1) decentralizing the provision of rapid HIV tests and provider-initiated voluntary testing to the level of community health posts, and 2) delivering HIV education to pregnant women through community health workers in their respective communities $(25,26)$. This project aims to achieve a long-term, sustainable increase in HIV testing rates among pregnant women in District 6.1, and eventually all of Managua, by integrating regular providerinitiated counseling and testing with rapid tests into day-to-day prenatal care within the current public health care system.

\section{Limitations}

The current study had a number of limitations related to the nature of the available data. First, the databases used were a collection of aggregate data, which precluded knowledge of demographics or risk factors of the population receiving HIV tests. In addition, the aggregate data only provided a view of the total number of HIV tests and initial prenatal visits during a defined period, which limited the ability to link individual tests with individual patients. Second, the databases only included the number of HIV tests carried out in the public health system. Some women may receive prenatal care in the public system but go to the private sector for an HIV test. The aggregate nature of the data also eliminated the possibility of determining the number of women who may have been tested more than once during their pregnancy. Third, in the Managua department data, one health center had to be excluded from the analysis because 1) there were no data on HIV testing for the 363 pregnant women it provided with initial prenatal care, according to the 2010 SILAIS database, and 2) in the 2011 database the health center was missing altogether. Fourth, a difference in the denominators used in calculating the percentages of pregnant women tested precludes a direct comparison between the current data and the WHO data referenced in this report. WHO reported percentages of pregnant women tested based on a denominator of estimated number of pregnant women, while the percentages calculated in this report for Managua and District 6.1 used the number of pregnant women who attended at least one prenatal visit as the denominator. Fifth, no objective data were available for evaluating how many of the women tested actually received their results. This is an important data point to capture, as any effort to increase HIV testing rates should also incorporate a mechanism to ensure that women are aware of their serostatus. Finally, the authors were unable to accurately assess the number of vertical transmission cases for 2010-2011 due to the two-year window required for case confirmation.

\section{Recommendations}

Increasing the uptake of HIV testing of pregnant women in District 6.1; Managua, Nicaragua; and the entire PanAmerican region will require a multipronged approach. The limitations presented in this study suggest it may be prudent to rethink the way testing data are captured within individual patient charts as well as within the district-level and SILAIS databases to more accurately assess progress toward the goal of $>95 \%$ testing. Initiatives to increase the education and knowledge of pregnant women with regard to the importance of HIV testing, appropriately adapted for each population, should be undertaken. In addition, instituting provider-initiated testing and counseling may increase the likelihood that a woman receives an HIV test.

Streamlining the testing process for the pregnant woman by decentralizing the availability of HIV rapid testing to local health posts, to avoid the need for additional laboratory visits, may increase the likelihood of her being tested. In addition to piloting and evaluating local initiatives to increase the percentage of pregnant women getting tested, governments and health officials could benefit from studying and drawing from programs in other countries in the region with higher testing uptake to improve programs and policies in their own countries.

\section{Conclusions}

The results of this retrospective epidemiologic study in Managua, Nicaragua, and in a single health district (District 6.1), revealed the percentage of pregnant women receiving an HIV test increased from 2010 to 2011 but the number of incident cases remains low. At the district level, the most notable increase occurred in February 2011, coinciding with health fairs promoting HIV testing. However, these increased rates were not sustained throughout 2011. Overall, testing rates appear to be moving in a positive direction but have failed to reach the $>95 \%$ testing coverage recommended by PAHO. Therefore, the authors of the current study believe that despite positive trends in Managua and District 6.1, new mechanisms are needed to achieve improvements in testing rates that are sustainable long term. The results of this report could be used to demonstrate the continued need to evaluate systems and expand efforts to achieve optimal coverage and ultimately interrupt the transmission of HIV from mother to child.

Acknowledgments. The authors thank the Jay Weiss Center for Social Medicine and Health Equity for the funding to make this project possible, and all of the staff at SILAIS Managua and the District 6.1 health center who assisted with the project.

Funding. Grant money was provided by the Jay Weiss Center for Social Medicine and Health Equity at the University of Miami (Miami, FL, USA).

Conflict of interest. None. 


\section{REFERENCES}

1. Joint United Nations Programme on HIV/ AIDS. Global report: UNAIDS report on the global AIDS epidemic. Geneva: UNAIDS; 2010. Available from: http://www.unaids. org/globalreport/global_report.htm Accessed 11 March 2011.

2. Mahy M, Stover J, Kiragu K, Hayashi C, Akwara P, Luo C, et al. What will it take to achieve virtual elimination of mother-to-child transmission of HIV? An assessment of current progress and future needs. Sex Transm Infect. 2010;86 Suppl 2:ii48-55.

3. Pan American Health Organization. Regional initiative for elimination of mother-to-child transmission of HIV and congenital syphilis in Latin America and the Caribbean: concept document for the Caribbean. Washington: PAHO; 2010. Pp. 1-23. Available from: http:// www2.paho.org/hq/dmdocuments/2010/Re gional $\% 20$ Initiative $\% 20$ for $\% 20$ Elimination $\% 20$ Concept $\% 20$ Document $\% 20$ for $\% 20$ the $\% 20$ Caribbean.pdf Accessed 20 December 2011.

4. World Bank. World development indicators database [Internet]. Washington: World Bank; 2011. Available from: http://siteresources. worldbank.org/DATASTATISTICS/Resources/GDP.pdf Accessed 20 December 2011. Pp. 1-4.

5. Central Intelligence Agency (US). The World Factbook. Central America and Caribbean: Nicaragua [Internet]. Washington: CIA; 2012. Available from: https://www.cia.gov/li brary/publications/the-world-factbook/ geos/nu.html Accessed 7 October 2012.

6. Comisión Nicaragüense del SIDA. Informe nacional sobre los progressos realizados en la aplicación del UNGASS: Nicaragua. Managua: CONISIDA; 2010. Pp. 1-46. Available from: http://www.unaids.org/en/dataanal ysis/knowyourresponse/countryprogressre ports/2010countries/nicaragua_2010_coun try_progress_report_es.pdf Accessed 24 February 2012.

7. Matute AJ, Delgado E, Amador JJ, Hoepelman AI. The epidemiology of clinically apparent HIV infection in Nicaragua. Eur J Clin Microbiol Infect Dis. 2008;27(2): 105-8.

8. United States Agency for International Development. HIV/AIDS health profile: Nicaragua [Internet]. Washington: USAID; 2010. Available from: http://www1.usaid.gov/ our_work/global_health/aids/Coun tries/lac/nicaragua_profile.pdf Accessed 20 December 2011.
9. Comisión Nicaragüense del SIDA. Plan estratégico nacional de ITS, VIH y SIDA 20062010. Managua: CONISIDA; 2006. Available from: http://aidstar-one.com/focus_ar eas/prevention/resources/national_strategic_plans Accessed 20 December 2011.

10. Agencia ACAN-EFE. Gobierno advierte que VIH es un problema para el desarrollo de Nicaragua. Managua: La Prensa (Nicaragua); 2011. Available from: http://www.laprensa. com.ni/2011/12/01/ambito/82493-gobiernoadvierte-que-vih

11. Elizondo J, Shultz JM, Baum MK, Herrera G. The epidemiology of AIDS and HIV infection in Costa Rica. Bull Pan Am Health Organ. 1993;27(2):145-50.

12. United States Agency for International Development. HIV/AIDS: countries [Internet]. Washington: USAID; 2010. Available from: http://transition.usaid.gov/our_work/ global_health/aids/Countries/index.htm Accessed 24 February 2012.

13. Orozco M, Pedraza Fariña LG. HIV/AIDS policy in Nicaragua: a civil society perspective. New York: Open Society Institute; 2008. Pp. 1-46. Available from: http://www.open societyfoundations.org/reports/hivaids-pol icy-nicaragua-civil-society-perspective Accessed 20 December 2011.

14. Espinoza $H$, Sequeira $M$, Domingo $G$, Amador JJ, Quintanilla M, de los Santos T. Management of the HIV epidemic in Nicaragua: the need to improve information systems and access to affordable diagnostics. Bull World Health Organ. 2011;89(8):619-20.

15. Pérez-Rosales MD. Situación epidemiológica del VIH y otras enfermedades prevalentes en la region. Washington: Pan American Health Organization; 2011. Available from: http:// www.tecnologias-ova.com/tutores / Documentos/presentacion4.pdf Accessed 24 February 2012.

16. Committee on Pediatric AIDS (US). HIV testing and prophylaxis to prevent mother-tochild transmission in the United States. Pediatrics. 2008;122(5):1127-34.

17. Instituto Nacional de Información y Desarrollo (NI). VII Censo de población y IV de vivienda: censo 2005. Resumen censal (23 de Noviembre del 2006). Managua: INIDE; 2006. Available from: http://www.inide.gob.ni/ censos2005/CifrasCompleto.pdf Accessed 22 July 2012.

18. Ministerio de Salud, Sistema Local de Atención Integral en Salud-Managua (NI). Plan de emergencia sanitario local, Distrito VI. Managua: MS/SILAIS; 2003.

19. Hensen B, Baggaley R, Wong VJ, Grabbe KL, Shaffer N, Lo YR, et al. Universal voluntary HIV testing in antenatal care settings: a review of the contribution of provider-initiated testing \& counselling. Trop Med Int Health. 2012;17(1):59-70.

20. Malaju MT, Alene GD. Assessment of utilization of provider-initiated HIV testing and counseling as an intervention for prevention of mother to child transmission of HIV and associated factors among pregnant women in Gondar town, North West Ethiopia. BMC Public Health. 2012;12:226.

21. World Health Organization. Global HIV/ AIDS response: epidemic update and health sector progress towards Universal Access. Progress Report 2011. Geneva: WHO; 2011. Pp. 1-233. Available from: http://www. who.int/hiv/pub/progress_report2011/en/ index.html Accessed 7 October 2012.

22. Meiberg AE, Bos AE, Onya HE, Schaalma HP. Fear of stigmaticization as barrier to voluntary HIV counselling and testing in South Africa. East Afr J Public Health. 2008;5(2):49-54

23. Ostermann J, Reddy EA, Shorter MM, Muiruri C, Mtalo A, Itemba DK, et al. Who tests, who doesn't, and why? Uptake of mobile HIV counseling and testing in the Kilimanjaro Region of Tanzania. PLoS One. 2011;6(1):e16488.

24. Instituto Nacional de Información de Desarrollo; Ministerio de Salud (NI). Encuesta Nicaragüense de Demografía y Salud ENDESA 2006/07. Informe final. Managua: INIDE; 2008. Pp. 1-664. Available from: www.inide. gob.ni/endesa/InformeFinal07.pdf Accessed 22 July 2012.

25. Swider SM. Outcome effectiveness of community health workers: an integrative literature review. Public Health Nurs. 2002;19(1):11-20.

26. Webel AR, Okonsky J, Trompeta J, Holzemer WL. A systematic review of the effectiveness of peer-based interventions on health-related behaviors in adults. Am J Public Health. 2010;100(2):247-53.

Manuscript received on 9 April 2012. Revised version accepted for publication on 29 November 2012. 
RESUMEN Objetivo. Determinar y notificar la tasa de realización de pruebas de detección del VIH, los patrones obtenidos y el número de casos positivos en las mujeres embarazadas que recibieron asistencia prenatal ambulatoria, en Managua, Nicaragua.

Tasas de realización de pruebas de detección del VIH en mujeres embarazadas en Managua, Nicaragua, 2010-2011
Métodos. Se llevó a cabo un examen epidemiológico retrospectivo para evaluar las tasas de realización de pruebas de detección del VIH en mujeres embarazadas que acudieron a centros de salud de distrito en Managua en el 2010 y el 2011, centrándose en un solo distrito (distrito 6.1).

Resultados. El 39,4\% de las mujeres embarazadas que recibieron asistencia prenatal en los centros de salud de Managua en el 2010 se sometieron a pruebas de detección del VIH, y esta cifra aumentó a 49,8\% en $2011(P<0,001 ; \Phi=0,10)$. En el 2010, 27 mujeres embarazadas de Managua presentaron resultados positivos en las pruebas de detección del VIH, lo que corresponde a $0,17 \%$ de las que se sometieron a estas pruebas; en el 2011, 31 tuvieron resultados positivos, es decir, 0,12\% de las embarazadas a las que se realizaron pruebas de detección del VIH. Las comparaciones entre el 2010 y el 2011 en el distrito 6.1 reflejan un aumento de las mujeres que se sometieron a pruebas de detección del VIH de 24,2\% en 2010 a 49,3\% en $2011(P<0,001 ; \Phi=0,26)$. En ese distrito, 2 mujeres embarazadas presentaron resultados positivos en el 2010 y 3 en el 2011, lo que corresponde, respectivamente, a 0,32\% y 0,13\% de las mujeres embarazadas a las que se les realizaron dichas pruebas.

Conclusiones. A pesar de las mejoras considerables en las tasas de realización de pruebas de detección del VIH entre el 2010 y el 2011, las cifras se mantuvieron por debajo de la meta recomendada (>95\%) por la Organización Panamericana de la Salud (OPS) para lograr la eliminación virtual de la transmisión maternoinfantil para el 2015. Los patrones de realización de pruebas evidenciaron que las tasas aumentaron en coincidencia con una feria de salud en el distrito 6.1, aunque los efectos duraron poco. Por consiguiente, es necesario utilizar nuevas estrategias para reforzar las pruebas de detección sistemática del VIH prenatales en Managua y en el distrito 6.1.

Palabras clave Seroprevalencia de VIH; mujeres embarazadas; serodiagnóstico del sida; Nicaragua. 